Fetal Diagnosis and Therapy
Fetal Diagn Ther 2012;32:156-165

DOI: $\underline{10.1159 / 000338655}$
Received: February 28, 2012

Accepted after revision: March 29, 2012

Published online: July 26, 2012

\title{
Birthweight with Gestation and Maternal Characteristics in Live Births and Stillbirths
}

\author{
Leona C.Y. Poon ${ }^{a}$ Nicola Volpe ${ }^{a, b}$ Brunella Muto ${ }^{a, b}$ Argyro Syngelaki $^{a}$ \\ Kypros H. Nicolaides ${ }^{a, b}$ \\ ${ }^{a}$ Harris Birthright Research Centre for Fetal Medicine, King's College Hospital, and ${ }^{b}$ Department of Fetal Medicine, \\ University College Hospital, London, UK
}

\section{Key Words}

Normal range $\cdot$ Birthweight percentiles $\cdot$ Small for

gestation $\cdot$ Stillbirth $\cdot$ Pyramid of antenatal care

\begin{abstract}
Objective: To establish a normal range of birthweight with gestational age (GA) at delivery and examine the contribution of maternal characteristics in defining growth restriction in stillbirths. Methods: In 69,895 normal singleton pregnancies, regression analysis was used to determine the association of birthweight with GA and maternal characteristics. The proportion of 290 stillbirths classified as small for GA depending on inclusion or exclusion of maternal characteristics was determined. Results: In normal pregnancies, there was a polynomial association between birthweight and GA. Birthweight increased with maternal weight, height and parity and was lower in Africans and South Asians than in Caucasians. Birthweight for GA was reduced in antepartum stillbirths $(n=243 ; p<0.0001)$ but not in intrapartum stillbirths ( $n=47 ; p=0.334$ ). There was no significant difference in the proportion of antepartum stillbirths with birthweight below the 10th percentile when birthweight was corrected for GA only compared to correction for GA and maternal characteristics (53.1 vs. $54.3 \%$ ). The birthweight was
\end{abstract}

below the 10th percentile in $71.8 \%$ of antepartum stillbirths at $<32$ weeks' gestation, in $47.2 \%$ at $33-36$ weeks and in $31.5 \%$ at $\geq 37$ weeks. Conclusion: Correction of birthweight for maternal characteristics does not alter the proportion of stillbirths that are small for GA.

Copyright $\odot 2012$ S. Karger AG, Basel

\section{Introduction}

Impaired placentation is associated with the development of preeclampsia, fetal growth restriction and stillbirth. In defining the contribution of fetal growth restriction to stillbirth and the consequent development of strategies for prevention of this pregnancy complication, it is essential to determine normal growth with gestational age (GA). Previous studies have reported that fetal growth is affected by several maternal characteristics, including racial origin, weight, height and parity [1-3]. However, it is uncertain whether correction of birthweight for GA by maternal characteristics improves the proportion of stillbirths that can be classified as growth restricted.

The aims of this study are firstly, to establish a normal range of birthweight with GA at delivery; secondly, to ex-

\section{KARGER \\ Fax +4161306 1234 \\ E-Mail karger@karger.ch}

www.karger.com (c) 2012 S. Karger AG, Basel

$1015-3837 / 12 / 0323-0156 \$ 38.00 / 0$

Accessible online at:

www.karger.com/fdt
Prof. K. H. Nicolaides

Harris Birthright Research Centre for Fetal Medicine, King's College Hospital Denmark Hill

London SE5 9RS (UK)

Tel. +44203299 8256, E-Mail kypros@fetalmedicine.com 
amine the contribution of maternal characteristics to birthweight for GA, and thirdly, to compare the proportion of stillbirths that are classified as small for GA (SGA) depending on inclusion or exclusion of maternal characteristics in defining birthweight percentiles for GA.

\section{Methods}

The study population consisted of 75,397 singleton pregnancies from King's College Hospital, University College London Hospital and Medway Maritime Hospital Kent. All women attended for their routine first hospital visit in pregnancy at 11-13 weeks' gestation. In this visit, we recorded maternal characteristics, including age, racial origin (Caucasian, African, South Asian, East Asian or mixed), history of medical conditions, parity (number of previous pregnancies ending at or after 24 weeks) and measured weight in $\mathrm{kg}$ and height in $\mathrm{cm}$. We also performed a transabdominal ultrasound scan to determine GA from the measurement of the fetal crown-rump length [4], to diagnose any major fetal abnormalities, and to measure fetal nuchal translucency thickness as part of combined testing with serum free $\beta$-human chorionic gonadotropin and pregnancy-associated plasma protein A in screening for aneuploidies [5]. Data on pregnancy outcome were collected from the hospital maternity records or their general medical practitioners. Written informed consent was obtained from the women agreeing to participate in a study on adverse pregnancy outcome, which was approved by the Ethics Committee of each participating hospital.

The inclusion criteria for establishment of a normal range of birthweight for GA were: firstly, delivery of live birth of phenotypically normal neonate at or after 24 weeks' gestation, secondly, no maternal pre-pregnancy hypertension or diabetes mellitus, and thirdly, no preeclampsia, gestational diabetes mellitus (GDM) or iatrogenic delivery for fetal growth restriction in the current pregnancy.

Stillbirths included both antepartum and intrapartum deaths of phenotypically normal neonates occurring at or after 24 weeks' gestation. Antepartum stillbirth was defined as fetal death before the onset of labor, and in such cases the diagnosis was essentially made by ultrasonography in women presenting with reduced or absent fetal movements. Intrapartum stillbirth was defined as fetal death after the onset of labor and before birth, and in these cases there was ultrasonographic or cardiotocographic evidence that the fetus was alive at the onset of labor. We included all cases irrespective of maternal pre-pregnancy disease or pregnancy complication.

In our hospitals, two ultrasound scans are performed routinely in all patients: one at 11-13 weeks' gestation and another at 20-23 weeks. Subsequent scans are carried out when there are clinical indications, including the suspicion of an SGA fetus. If such scans confirm the diagnosis of fetal growth restriction, based on a combination of biometry, amniotic fluid volume and fetal Doppler indices, iatrogenic delivery may be undertaken. The definition of preeclampsia was that of the International Society for the Study of Hypertension in Pregnancy [6]. In our hospitals, screening for GDM was based on a two-step approach. Random plasma glucose was measured at 24-28 weeks' gestation, and if the concentration was more than $6.7 \mathrm{mmol} / \mathrm{l}$, an oral glucose tolerance test was carried out within the subsequent 2 weeks. The diagnosis of GDM was made if the fasting plasma glucose level was at least $6 \mathrm{mmol} / \mathrm{l}$ or the plasma glucose level $2 \mathrm{~h}$ after the oral administration of $75 \mathrm{~g}$ glucose was $7.8 \mathrm{mmol} / \mathrm{l}$ or more [7].

This study is part of a research program on the early prediction of pregnancy complications. In a previous publication of 33,602 pregnancies, we established a reference range of birthweight with GA at delivery [8]. In this study of 69,895 pregnancies, we have included the normal population from the previous study to establish a normal range of birthweight with GA at delivery.

\section{Statistical Analysis}

A normal range of birthweight for GA was established from the live births fulfilling the inclusion criteria. GA at delivery was centered by subtracting 40 from GA in weeks. Linear regression analysis was used to determine the association of birthweight with GA. The standard deviation (SD) was estimated by regressing the absolute residuals on the estimated mean birthweight [9], which was subsequently multiplied by $\sqrt{ }(\pi / 2)(1.253314)$ to calculate the fitted SD. The observed birthweight was then expressed as z-score (difference between observed and expected divided by fitted SD) and percentile corrected for GA. Regression analysis was used to examine the association between GA corrected birthweight $\mathrm{z}$-scores and maternal weight, height, racial origin and parity. Maternal weight was centered by subtracting $69 \mathrm{~kg}$ and maternal height was centered by subtracting $164 \mathrm{~cm}$. The observed birthweight was then expressed as z-score and percentile corrected for GA and maternal characteristics. Unpaired t test was used to compare the birthweight z-scores for GA with and without correction for maternal characteristics between the normal population and stillbirths. Regression analysis was used to examine the association between birthweight z-scores and GA in the outcome groups. The proportion of stillbirths with birthweight below the 5th, 10th and 20th percentiles for GA with and without correction for maternal characteristics was determined and compared by the $\chi^{2}$ test. The detection rates and false-positive rates for stillbirth in screening by birthweight for GA with and without correction for maternal characteristics were determined by receiver operating characteristics curve (ROC), and the areas under the ROC were compared [10].

The statistical software package SPSS 20.0 (SPSS Inc., Chicago, Ill., USA) and Medcalc (Medcalc Software, Mariakerke, Belgium) were used for the data analyses.

\section{Results}

During the study period, first-trimester combined screening for aneuploidies was carried out in 79,694 singleton pregnancies. We excluded 4,297 (5.4\%) cases because they had missing outcome data $(n=2,407)$, the pregnancies resulted in miscarriage before 24 weeks of gestation, they were terminated or they resulted in the birth of babies with major defects $(n=1,890)$. In the remaining 75,397 singleton pregnancies, there were 75,104 live births and 293 (0.4\%) stillbirths. In three of the still- 
Table 1. Characteristics in the study population

\begin{tabular}{lccc}
\hline Variables & Live birth $(\mathrm{n}=75,104)$ & Stillbirth $(\mathrm{n}=290)$ & $\mathrm{p}$ value \\
\hline Median maternal age, years & $31.3(26.8-35.2)$ & $30.9(25.5-36.2)$ & 0.772 \\
Median weight, kg & $65.4(59.0-75.4)$ & $70.0(60.0-81.5)$ & $<0.0001^{*}$ \\
Median height, cm & $164(160-168)$ & $165(159-167)$ & 0.061 \\
Racial origin & & & $<0.0001^{*}$ \\
$\quad$ Caucasian & $56,965(75.8)$ & $180(62.1)$ & $<0.0001^{*}$ \\
African & $11,037(14.7)$ & $89(30.7)$ & 0.701 \\
South Asian & $3,600(4.8)$ & $12(4.1)$ & 0.195 \\
East Asian & $1,776(2.4)$ & $3(1.0)$ & 0.949 \\
Mixed & $1,726(2.3)$ & $6(2.1)$ & 0.997 \\
Parity & & & 0.997 \\
Nulliparous & $36,914(49.2)$ & $142(49.0)$ & $0.020^{*}$ \\
Parous & $38,190(50.8)$ & $148(51.0)$ & $0.015^{*}$ \\
Cigarette smoker & $7,528(10.0)$ & $42(14.5)$ & $<0.0001^{*}$ \\
Assisted conception & $2,749(3.7)$ & $18(6.2)$ & $<0.0001^{*}$ \\
Pre-pregnancy medical conditions & $1,310(1.7)$ & $23(7.9)$ & $<0.0001^{*}$ \\
Chronic hypertension & $830(1.1)$ & $8(2.5)$ & $<0.0001^{*}$ \\
Diabetes mellitus & $521(0.7)$ & $44(15.2)$ & $<0.0001^{*}$ \\
Pregnancy complications & $4,104(5.5)$ & $42(14.5)$ & 0.230 \\
$\quad$ Preeclampsia & $1,656(2.2)$ & $2(0.7)$ & \\
Gestational diabetes & $1,353(1.8)$ & &
\end{tabular}

Figures in parentheses indicate percentages or interquartile range. Comparisons between live births and stillbirths were by $\chi^{2}$ or Fisher exact test for categorical variables and Mann-Whitney $U$ test for continuous variables. ${ }^{*} \mathrm{p}<0.05$, significant.

births, the fetal death was the consequence of maternal death (car accident in two and eclampsia in one), and these were excluded from further analysis. In the remaining 290 stillbirths, fetal death was antepartum in 243 (83.8\%) and intrapartum in 47 (16.2\%).

In the establishment of the normal range of birthweight for GA, we included only 69,895 (93.1\%) of the 75,104 live births, after exclusion of pregnancies because of maternal chronic hypertension $(n=830)$, diabetes mellitus $(n=521)$, preeclampsia $(n=1,656), \operatorname{GDM}(n=1,353)$, or iatrogenic delivery for fetal growth restriction ( $\mathrm{n}=$ 1,352). We excluded $176(28.5 \%)$ of the 618 pregnancies that delivered at $<32$ weeks, 783 (22.9\%) of 3,425 at 32-36 weeks and 4,250 (6.0\%) of 71,061 at $\geq 37$ weeks.

The characteristics of the pregnancies with 75,104 live births and 290 stillbirths are presented in table 1 . In the group with stillbirth, compared to those with live birth, there was a higher prevalence of women of African racial origin, cigarette smokers, those with chronic hypertension, diabetes mellitus, preeclampsia, those conceiving with assisted conception techniques, and the weight of the women was higher and the birthweight lower.

\section{Normal Population}

In the normal population of 69,895 live births, there was a significant polynomial association between neonatal birthweight and GA (fig. 1; table 2):

Estimated mean birthweight $=3,459.382+156.069 \times$ $(\mathrm{GA}-40)-11.784 \times(\mathrm{GA}-40)^{2}-0.674 \times(\mathrm{GA}-40)^{3}$; $\mathrm{R}^{2}=0.350, \mathrm{p}<0.0001$.

Fitted SD $=\sqrt{ }(\pi / 2) \times[-22.903+0.151 \times($ estimated mean birthweight) $-1.393 \mathrm{e}-05 \times$ (estimated mean birthweight $)^{2}$.

Regression analysis demonstrated that GA-corrected birthweight $\mathrm{z}$-scores increased with maternal weight $(\mathrm{p}<$ $0.0001)$, height $(p<0.0001)$ and parity $(p<0.0001)$, and were lower in women of African $(\mathrm{p}<0.0001)$ and South Asian $(\mathrm{p}<0.0001)$ racial origin than in Caucasians (table 3). The contributions of each maternal factor to birthweight in grams at 40 weeks' gestation are illustrated in table 3.

There was no significant difference in the proportion of live births with birthweight below the 5th, 10th and 20th percentiles when birthweight was corrected for GA only, compared to correction for GA and maternal characteristics (table 4). 
Table 2. Normal range of birthweight with GA at delivery

\begin{tabular}{|c|c|c|c|c|c|c|c|c|c|c|c|c|}
\hline $\begin{array}{l}\text { Gestation } \\
\text { week }\end{array}$ & Mean & Fitted SD & $1 s t$ & $3 \mathrm{rd}$ & 5 th & 10th & 20th & 80th & 90th & 95th & 97th & 99th \\
\hline 25 & 743.2 & 100.9 & 508.5 & 553.4 & 577.2 & 613.9 & 658.3 & 828.2 & 872.6 & 909.2 & 933.0 & 978.0 \\
\hline 26 & 815.5 & 112.6 & 553.5 & 603.7 & 630.2 & 671.1 & 720.7 & 910.2 & 959.8 & $1,000.7$ & $1,027.2$ & $1,077.4$ \\
\hline 27 & 920.8 & 129.3 & 619.9 & 677.5 & 708.0 & 755.0 & 811.9 & $1,029.6$ & $1,086.5$ & $1,133.5$ & $1,164.0$ & $1,221.6$ \\
\hline 30 & $1,394.7$ & 199.8 & 930.0 & $1,019.0$ & $1,066.1$ & $1,138.7$ & $1,226.6$ & $1,562.9$ & $1,650.8$ & $1,723.3$ & $1,770.5$ & $1,859.5$ \\
\hline 31 & $1,591.9$ & 226.8 & $1,064.4$ & $1,165.4$ & $1,218.9$ & $1,301.3$ & $1,401.1$ & $1,782.8$ & $1,882.6$ & $1,964.9$ & $2,018.4$ & $2,119.5$ \\
\hline 32 & $1,802.0$ & 254.0 & $1,211.0$ & $1,324.2$ & $1,384.1$ & $1,476.4$ & $1,588.2$ & $2,015.8$ & $2,127.5$ & $2,219.8$ & $2,279.8$ & $2,393.0$ \\
\hline 33 & $2,020.8$ & 280.8 & $1,367.5$ & $1,492.6$ & $1,558.9$ & $1,660.9$ & $1,784.5$ & $2,257.2$ & $2,380.7$ & $2,482.7$ & $2,549.0$ & $2,674.1$ \\
\hline 34 & $2,244.4$ & 306.4 & $1,531.5$ & $1,668.1$ & $1,740.4$ & $1,851.7$ & $1,986.5$ & $2,502.3$ & $2,637.1$ & $2,748.5$ & $2,820.8$ & $2,957.3$ \\
\hline 39 & $3,292.2$ & 403.3 & $2,354.1$ & $2,533.7$ & $2,628.9$ & $2,775.4$ & $2,952.8$ & $3,631.6$ & $3,809.0$ & $3,955.5$ & $4,050.7$ & $4,230.3$ \\
\hline 40 & $3,459.4$ & 415.2 & $2,493.5$ & $2,678.5$ & $2,776.5$ & $2,927.3$ & $3,110.0$ & $3,808.8$ & $3,991.4$ & $4,142.3$ & $4,240.2$ & $4,425.2$ \\
\hline 41 & $3,603.0$ & 424.6 & $2,615.2$ & $2,804.4$ & $2,904.6$ & $3,058.8$ & $3,245.6$ & $3,960.4$ & $4,147.2$ & $4,301.4$ & $4,401.6$ & $4,590.8$ \\
\hline 42 & $3,719.0$ & 431.7 & $2,714.6$ & $2,907.0$ & $3,008.9$ & $3,165.7$ & $3,355.6$ & $4,082.3$ & $4,272.3$ & $4,429.1$ & $4,531.0$ & $4,723.3$ \\
\hline 43 & $3,803.3$ & 436.6 & $2,787.7$ & $2,982.2$ & $3,085.2$ & $3,243.8$ & $3,435.9$ & $4,170.8$ & $4,362.8$ & $4,521.4$ & $4,624.5$ & $4,819.0$ \\
\hline
\end{tabular}

In figure $2 \mathrm{a}$ we compare the 5th, 50th and 95th percentiles of our normal population with those of a previous study in which birthweight was estimated by combining the weight of normal neonates at term with ultrasound-derived fetal growth charts for earlier gestations [11]. The values were similar.

Comparison of Birthweight Percentiles with Gestation in the Normal and Total Population

We used the same approach as described above for the normal population of 69,895 live births, to derive the regression equation and fitted SD of neonatal birthweight with GA for our total population of 75,104 live births. In figure $2 \mathrm{~b}$ we compare the 5 th, 50 th and 95 th percentiles of the normal and total populations. The 50th percentiles were similar for pregnancies at term, but at earlier gestations the values were lower for the total than in the normal population. The 5 th percentile in the total population was lower than in the normal population and the difference was inversely related to GA.

\section{Stillbirth}

The birthweight of antepartum and intrapartum stillbirths is illustrated in figure 3. Compared to the normal

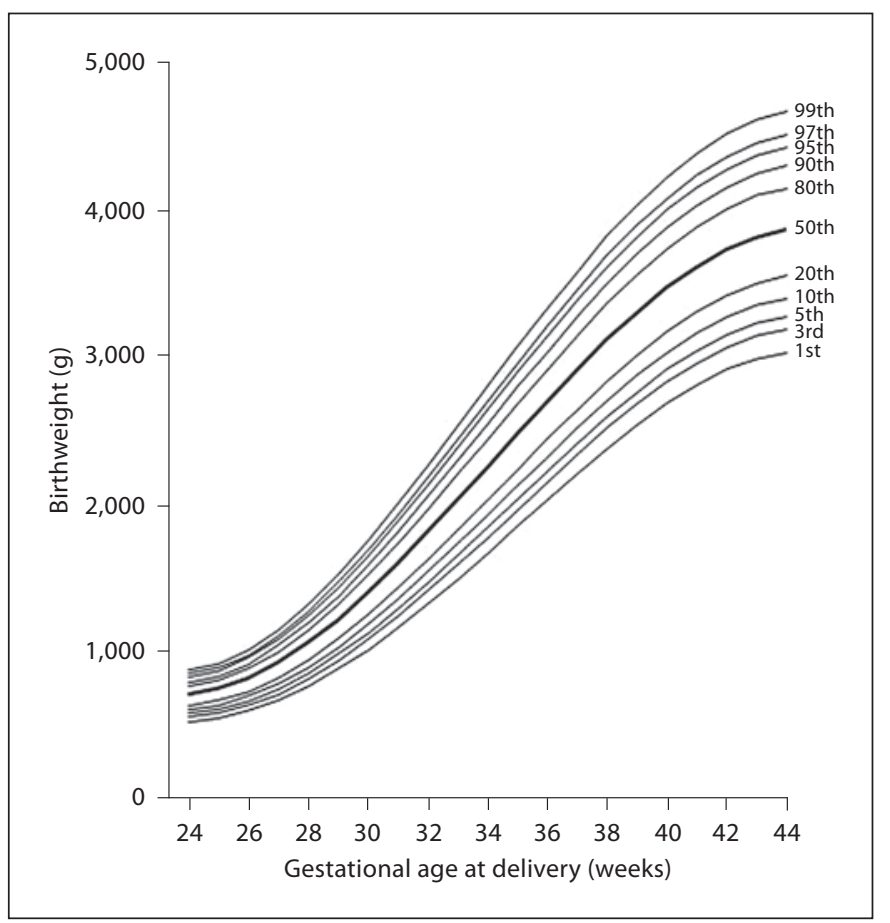

Fig. 1. The normal range of birthweight for GA at delivery. 
Table 3. Association between birthweight z-scores corrected for GA and maternal characteristics

\begin{tabular}{|c|c|c|c|c|}
\hline \multirow{2}{*}{$\begin{array}{l}\text { Estimated } \\
\text { birthweight } \\
\text { z-score }\end{array}$} & \multicolumn{3}{|c|}{ Maternal factors only } & \multirow{2}{*}{$\begin{array}{l}\text { Contribution } \\
\text { in grams at } 40 \text { weeks' } \\
\text { gestation }\end{array}$} \\
\hline & $\mathrm{b}$ & SE & $\mathrm{p}$ value & \\
\hline Intercept & -0.032043 & 0.006016 & $<0.0001$ & \\
\hline Weight - $69 \mathrm{~kg}$ & 0.016188 & 0.000337 & $<0.0001$ & +5.358 \\
\hline$(\text { Weight }-69 \mathrm{~kg})^{2}$ & -0.000160 & 0.000010 & $<0.0001$ & -0.053 \\
\hline Height $-164 \mathrm{~cm}$ & 0.018545 & 0.000583 & $<0.0001$ & +6.138 \\
\hline \multicolumn{5}{|l|}{ Parity } \\
\hline Nulliparous & 0 & & & \\
\hline Para 1 & 0.255069 & 0.008184 & $<0.0001$ & +84.4 \\
\hline Para 2 & 0.265757 & 0.011865 & $<0.0001$ & +88.0 \\
\hline Para 3 & 0.259039 & 0.019338 & $<0.0001$ & +85.8 \\
\hline Para $\geq 4$ & 0.213405 & 0.026473 & $<0.0001$ & +70.6 \\
\hline \multicolumn{5}{|l|}{ Racial origin } \\
\hline Caucasian & 0 & & & \\
\hline African & -0.332870 & 0.010715 & $<0.0001$ & -110.2 \\
\hline South Asian & -0.265004 & 0.017676 & $<0.0001$ & -87.8 \\
\hline
\end{tabular}

Fitted SD $=(\pi / 2) \times[0.745477+0.120971 \times($ estimated birthweight $\mathrm{z}$-score $)+0.087024 \times($ estimated birthweight z-score $)^{2}$.

Table 4. Proportion of live births with birthweight below the 5th, 10th and 20th percentiles for GA with and without correction for maternal characteristics in the total population and in normal pregnancies

\begin{tabular}{|c|c|c|c|c|c|c|}
\hline \multirow[t]{3}{*}{ Percentile } & \multicolumn{3}{|c|}{ Total population $(\mathrm{n}=75,104)$} & \multicolumn{3}{|c|}{ Normal pregnancies $(n=69,895)$} \\
\hline & \multicolumn{3}{|c|}{ correction for maternal factors } & \multicolumn{3}{|c|}{ correction for maternal factors } \\
\hline & no & yes & $\mathrm{p}$ value & no & yes & $\mathrm{p}$ value \\
\hline$<5$ th & $4,131(5.5)$ & $4,265(5.7)$ & 0.130 & $2,977(4.3)$ & $3,071(4.4)$ & 0.222 \\
\hline$<10$ th & $8,146(10.9)$ & $8,187(10.9)$ & 0.740 & $6,410(9.2)$ & $6,486(9.3)$ & 0.488 \\
\hline$<20$ th & $16,293(21.7)$ & $16,184(21.6)$ & 0.498 & $14,002(20.0)$ & $13,905(19.9)$ & 0.521 \\
\hline
\end{tabular}

Comparisons between birthweight correction for GA only vs. correction for GA and maternal characteristics were by $\chi^{2}$ test.

population, the birthweight z-scores for GA with and without correction for maternal characteristics were significantly reduced in antepartum stillbirths $(\mathrm{n}=243$; $\mathrm{p}<$ 0.0001; $\mathrm{p}<0.0001$ ) but not in intrapartum stillbirths ( $\mathrm{n}=$ $47 ; \mathrm{p}=0.334 ; \mathrm{p}=0.455$; table 5). There was significant association between birthweight $\mathrm{z}$-score with GA in antepartum stillbirths but not in intrapartum stillbirths (fig. 4).

There was no significant difference in the proportion of stillbirths with birthweight below the 5th, 10th and 20th percentiles when birthweight was corrected for GA only, compared to correction for GA and maternal characteristics (table 6).
The detection rates of stillbirth for false-positive rates of 5 and $10 \%$ in screening by birthweight corrected for GA were $35.9 \%$ (95\% CI 30.3-41.7) and 44.5\% (95\% CI 38.7-50.4), respectively. The respective detection rates after correction of birthweight for maternal characteristics were $37.9 \%$ (95\% CI 32.3-43.8) and 45.9\% (95\% CI 40.051.8). The area under the ROC for birthweight corrected for GA was not significantly improved by correction for maternal characteristics $(0.712,95 \%$ CI $0.709-0.715$ vs. $0.716,95 \%$ CI $0.713-0.719, \mathrm{p}=0.311)$. 


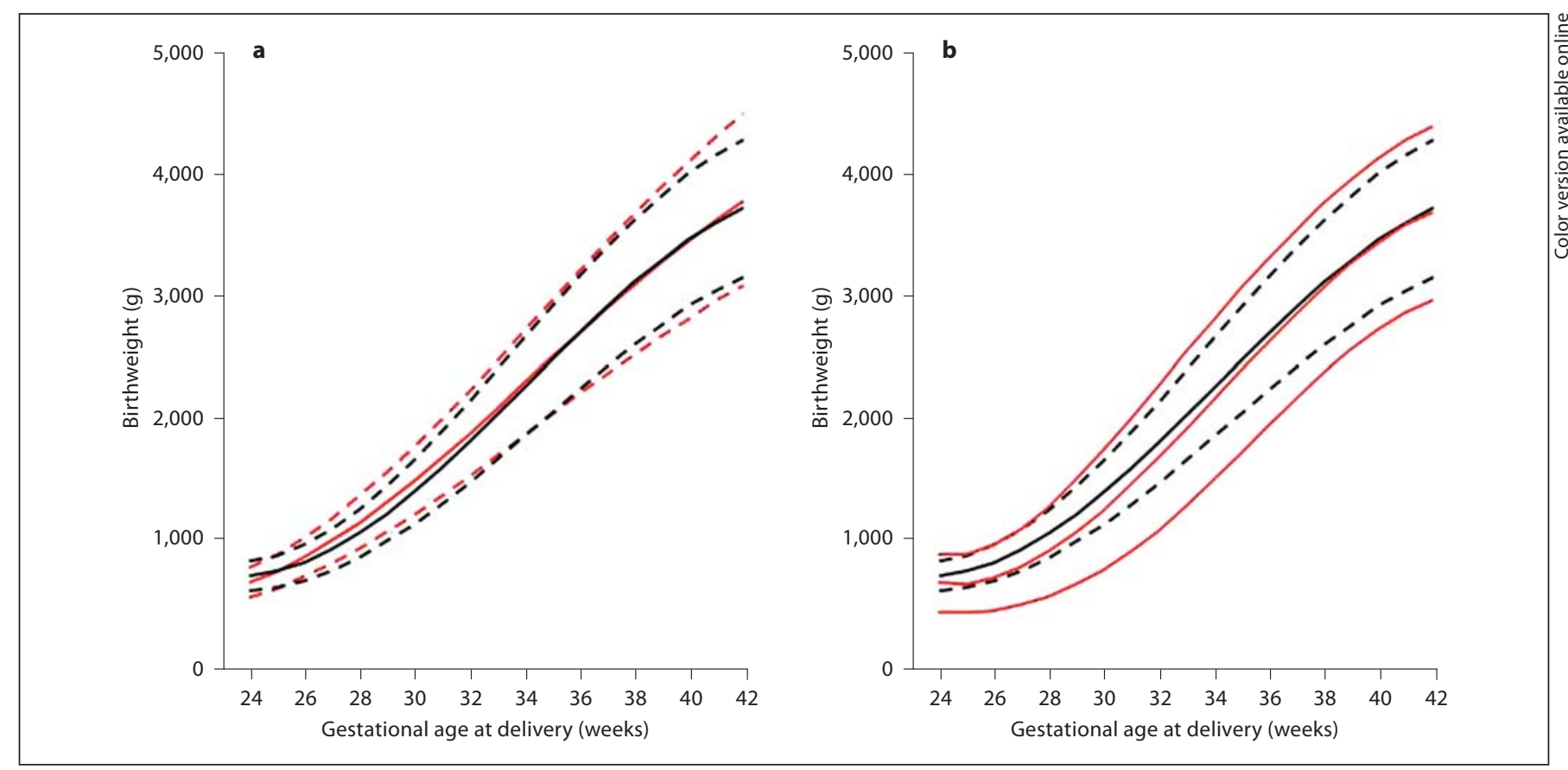

Fig. 2. The 5th, 50th and 95th percentiles of birthweight with GA in our normal population (black lines) and those of a previous study in which birthweight was estimated by combining the weight of normal neonates at term with ultrasound-derived fetal growth charts for earlier gestations (red lines; a) [10] and those in our total population (red lines; b). Colors refer to the online version only.

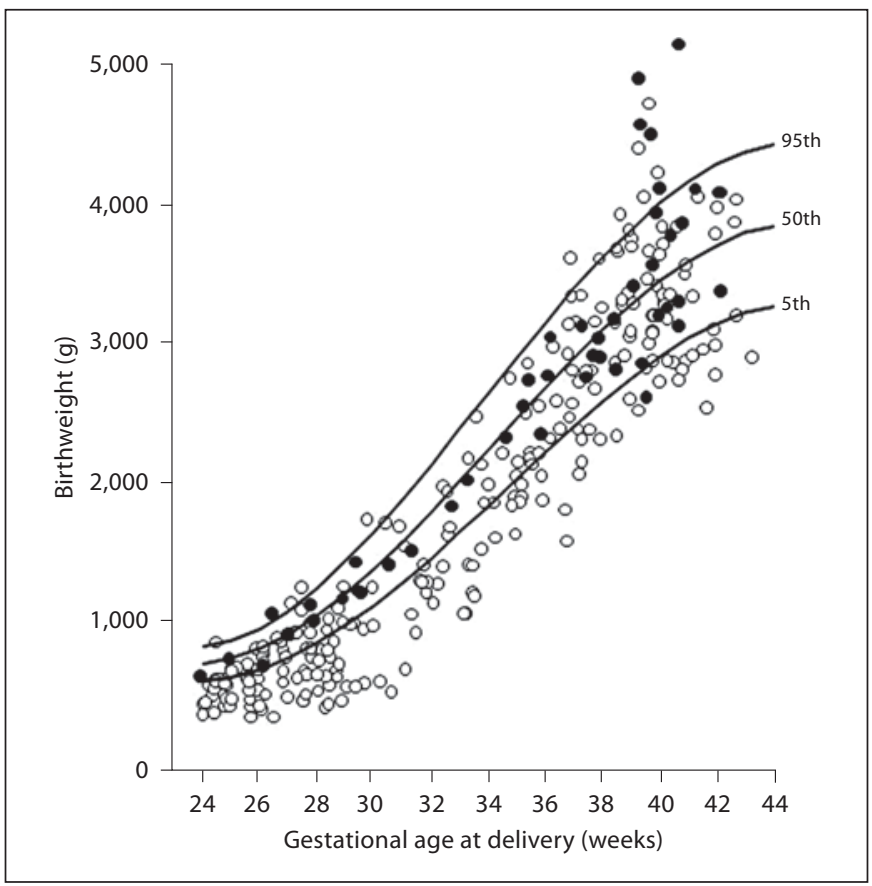

Fig. 3. Birthweight against GA at delivery in pregnancies complicated by antepartum stillbirth (open circles) and intrapartum stillbirth (solid dots), plotted on the 5 th, 50 th and 95 th percentiles of the normal range.

Birthweight in Live Births and Stillbirths

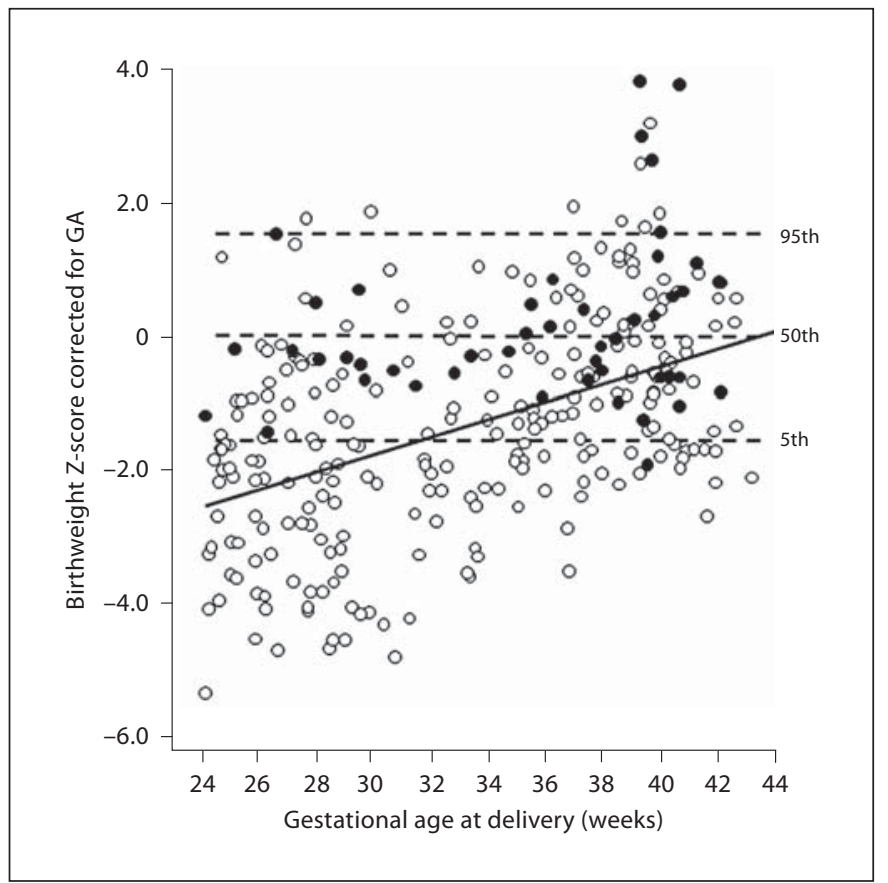

Fig. 4. Birthweight $\mathrm{z}$-score corrected for GA at delivery in pregnancies complicated by antepartum stillbirth (open circles and solid regression line) and intrapartum stillbirth (solid dots), plotted on the 5th, 50th and 95th percentiles of the normal range. 
Table 5. Mean and SD of birthweight z-score and Pearson correlation between birthweight z-score and GA at delivery in the live births and stillbirths

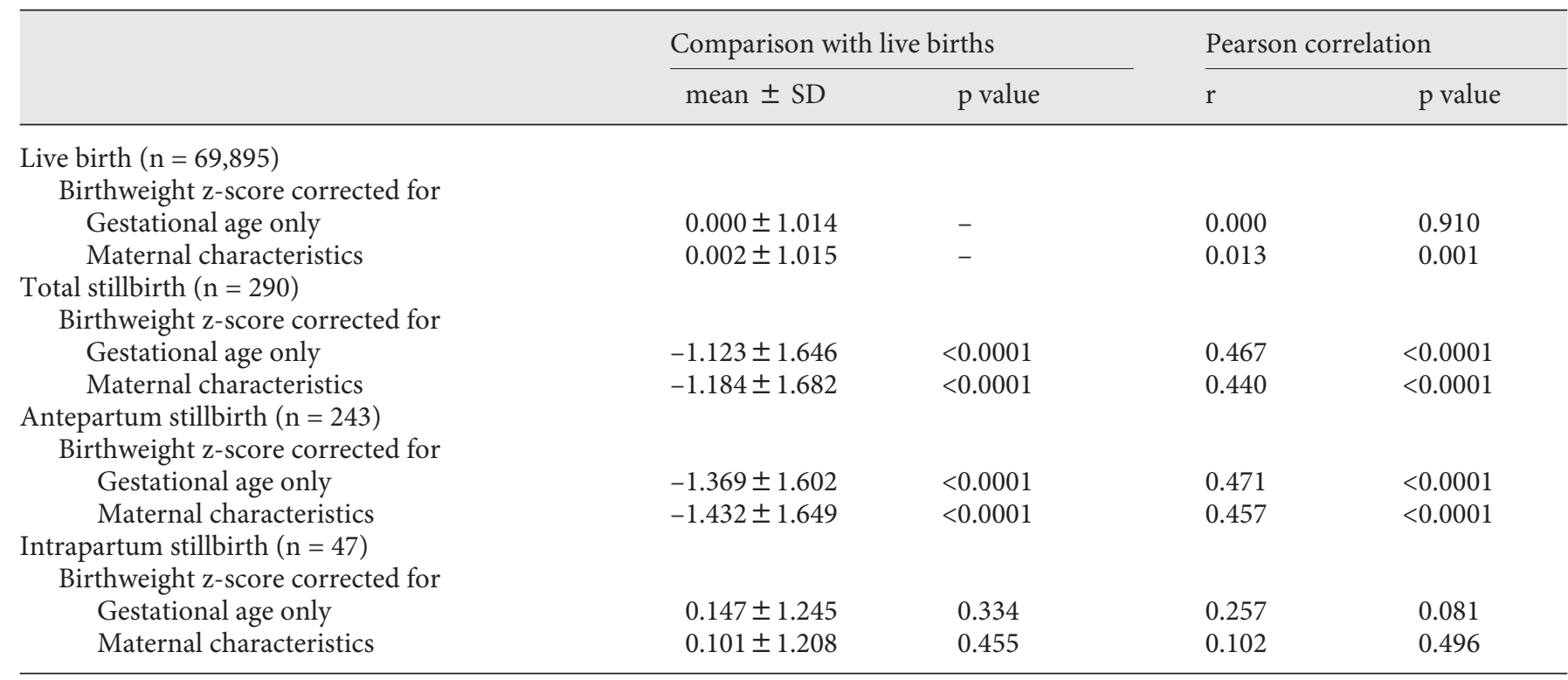

Table 6. Proportion of stillbirths with birthweight below the 5th, 10th and 20th percentiles for GA with and without correction for maternal characteristics

\begin{tabular}{|c|c|c|c|c|c|c|c|c|c|c|c|c|}
\hline \multirow[t]{3}{*}{ Percentile } & \multirow[t]{3}{*}{ Total } & \multicolumn{3}{|c|}{ Total stillbirth } & \multirow[t]{3}{*}{ Total } & \multirow{2}{*}{\multicolumn{3}{|c|}{$\begin{array}{l}\text { Antepartum stillbirth } \\
\text { correction for maternal factors }\end{array}$}} & \multirow[t]{3}{*}{ Total } & \multirow{2}{*}{\multicolumn{3}{|c|}{$\begin{array}{l}\text { Intrapartum stillbirth } \\
\text { correction for maternal factors }\end{array}$}} \\
\hline & & \multicolumn{3}{|c|}{ correction for maternal factors } & & & & & & & & \\
\hline & & no & yes & $\mathrm{p}$ value & & no & yes & $\mathrm{p}$ value & & no & yes & $\mathrm{p}$ value \\
\hline \multicolumn{13}{|l|}{$<5$ th } \\
\hline Total & 290 & $108(37.2)$ & $113(39.0)$ & 0.732 & 243 & $107(44.0)$ & $112(46.1)$ & 0.715 & 47 & $1(2.1)$ & $1(2.1)$ & 1.000 \\
\hline$<32$ weeks & 123 & $69(56.1)$ & $74(60.2)$ & 0.605 & 110 & $69(62.7)$ & $74(67.3)$ & 0.572 & 13 & $0(0.0)$ & $0(0.0)$ & - \\
\hline $32-36$ weeks & 61 & $20(33.3)$ & $21(34.4)$ & 0.848 & 53 & $20(37.7)$ & $21(39.6)$ & 0.842 & 8 & $0(0.0)$ & $0(0.0)$ & - \\
\hline$\geq 37$ weeks & 106 & $19(18.4)$ & $18(17.0)$ & 0.856 & 80 & $18(22.5)$ & $17(21.3)$ & 0.848 & 26 & $1(3.8)$ & $1(3.8)$ & 1.000 \\
\hline \multicolumn{13}{|l|}{$<10$ th } \\
\hline Total & 290 & $131(45.2)$ & $135(46.6)$ & 0.803 & 243 & $129(53.1)$ & $132(54.3)$ & 0.860 & 47 & $2(4.3)$ & $3(6.4)$ & 0.646 \\
\hline$<32$ weeks & 123 & $80(65.0)$ & $80(65.0)$ & 1.000 & 110 & $79(71.8)$ & $79(71.8)$ & 1.000 & 13 & $1(7.7)$ & $1(7.7)$ & 1.000 \\
\hline 32-36 weeks & 61 & $25(41.0)$ & $30(49.2)$ & 0.467 & 53 & $25(47.2)$ & $30(56.6)$ & 0.437 & 8 & $0(0.0)$ & $0(0.0)$ & - \\
\hline$\geq 37$ weeks & 106 & $26(24.5)$ & $25(23.6)$ & 0.872 & 80 & $25(31.3)$ & $23(28.8)$ & 0.863 & 26 & $1(3.8)$ & $2(7.7)$ & 0.552 \\
\hline \multicolumn{13}{|l|}{$<20$ th } \\
\hline Total & 290 & $162(55.9)$ & $164(56.6)$ & 0.883 & 243 & $155(63.8)$ & $153(63.0)$ & 0.925 & 47 & $7(14.9)$ & $11(23.4)$ & 0.432 \\
\hline$<32$ weeks & 123 & $91(74.0)$ & $86(69.9)$ & 0.570 & 110 & $89(80.9)$ & $85(77.3)$ & 0.619 & 13 & $2(15.4)$ & $1(7.7)$ & 0.539 \\
\hline $32-36$ weeks & 61 & $37(60.7)$ & $37(60.7)$ & 1.000 & 53 & $36(67.9)$ & $35(66.0)$ & 0.836 & 8 & $1(12.5)$ & $2(25.0)$ & 0.522 \\
\hline$\geq 37$ weeks & 106 & $34(32.1)$ & $41(38.7)$ & 0.389 & 80 & $30(37.5)$ & $33(41.3)$ & 0.746 & 26 & $4(15.4)$ & $8(30.8)$ & 0.323 \\
\hline
\end{tabular}

Comparisons between birthweight correction for GA only vs. correction for GA and maternal characteristics were by $\chi^{2}$ test. 


\section{Discussion}

This study has established a normal range of birthweight for GA at delivery in a large heterogeneous innercity unselected population of singleton pregnancies in which GA was determined by an ultrasound scan in early pregnancy. Birthweight increases with maternal weight, height and parity and is lower in women of African and South Asian racial origin than in Caucasians. In stillbirths, birthweight for GA is lower than in live births, but the proportion of stillbirths that are SGA is not altered by correction of birthweight for maternal characteristics.

\section{Normal Range of Birthweight for GA}

In the establishment of a normal range of birthweight for GA, we excluded pregnancies of women with chronic hypertension and diabetes mellitus and those complicated by fetal abnormalities, preeclampsia, GDM and severe fetal growth restriction requiring iatrogenic delivery. The association between these maternal and pregnancy conditions with abnormal fetal growth is well described [12$15]$, and in previous studies reporting on normal ranges these conditions have also been excluded [1-3]. This is particularly important for early gestations because a high proportion of pregnancies resulting in preterm birth are pathological. As illustrated in our study, exclusion of pathological pregnancies has a major impact on birthweight percentiles, which is particularly marked for preterm deliveries (fig. 2b).

Our study has demonstrated that by selecting a normal population, the median and SD of birthweight for GA and the effects of certain maternal characteristics are similar to those estimated in previous studies which combined data from normal pregnancies at term with ultrasonographically derived fetal growth charts [1-3].

\section{Stillbirth Prevalence and Risk Factors}

The rate of stillbirth in this study was $0.4 \%$, which is comparable to the UK national rate of $0.47 \%$ in 2009 [16]. In our study, $16 \%$ of the stillbirths were intrapartum. The reported relative proportion of intrapartum to antepartum stillbirth increases with the overall rate of stillbirth [17]. The estimated proportion of intrapartum stillbirths worldwide is $45 \%$, and this increases with the overall rate of stillbirth from about $14 \%$ for developed countries, where the stillbirth rate is about 3 per 1,000 births, to $57 \%$ in South Asia, where the stillbirth rate is 267 per 1,000 births [17].

The study has confirmed the known associations between certain maternal characteristics and increased risk for stillbirth, including African racial origin, high maternal weight, cigarette smoking, assisted conception, chronic hypertension, diabetes mellitus and preeclampsia. Large population-based studies reported that the risk of stillbirth is twice as high in African women, compared to Caucasians [16, 18], the risk increases with maternal weight [19-21], and it is higher in smokers than nonsmokers [22] and in pregnancies conceived by in vitro fertilization and ovulation induction than in spontaneous conceptions [23]. A systematic review examining the causes of stillbirth reported that chronic hypertension is associated with an increased risk with odds ratios of 1.52.7 [24]. Similarly, a UK national population-based cohort study of 2,359 pregnancies in women with diabetes mellitus reported a twofold increase in the risk of stillbirth compared to non-diabetic women [25]. A US population-based study reported that in pregnancies with preeclampsia the risk of stillbirth is increased by $70 \%$ [26].

\section{Correction of Fetal Weight for Maternal \\ Characteristics}

The proportion of stillbirths that can be classified as SGA was not improved by adjusting for maternal characteristics the birthweight for GA percentiles. This finding is in apparent contradiction to the results of previous studies which reported that infants classified as SGA by customized versus population-based birthweight standards have higher relative risks of perinatal mortality and morbidity [27-30]. However, a critical appraisal of customized birthweight standards demonstrated that their apparent benefit in improving the prediction of adverse perinatal outcomes is derived from their incorporation of intrauterine-based reference values at preterm ages rather than their adjustment for maternal characteristics [31]. Our results are in agreement with this suggestion because if we had used the percentiles derived from our total rather than the normal population, many of the preterm stillbirths would not have been identified as being growth restricted.

In women of African racial origin, birthweight is significantly lower than in Caucasian women after adjustment for maternal weight, height and parity. It could therefore be assumed that it is physiological for this racial group to produce smaller babies than Caucasians. The alternative view is that in women of African origin living in England the delivery of smaller babies is a consequence of pathological influences that would be masked by customized birthweight percentiles. We have previously reported that in women of African racial origin, after adjustment for other demographic and pregnancy charac- 
teristics, there is increased risk for several adverse pregnancy outcomes, including miscarriage, stillbirth, preeclampsia, fetal growth restriction and preterm birth [32-36]. In our population, $15 \%$ of women were of African racial origin, and this group contributed to $30 \%$ of the stillbirths.

\section{Implications of Our Findings for Strategies of Prevention of Stillbirth}

Any strategy aiming to reduce stillbirth in developed countries should primarily target antepartum deaths since these account for more than $80 \%$ of cases. Nevertheless, every effort should be made to also reduce intrapartum stillbirths particularly so because the majority is preventable by better obstetric care. The UK confidential enquiry on perinatal death has reported that a high proportion of intrapartum deaths were associated with avoidable factors [16].

In $45 \%$ of our antepartum stillbirths, the death occurred at less than 32 weeks' gestation, and in this group the birthweight was below the 10th percentile for GA in $72 \%$ of the cases. The combination of early gestation and low birthweight implies that in many of these cases fetal death may be unavoidable. When the diagnosis of earlyonset severe fetal growth restriction is made prenatally, the attending obstetricians in consultation with the parents could decide to avoid iatrogenic delivery because of the perceived high risk of neonatal death or severe handicap in survivors. A strategy for avoidance of such early stillbirths should focus on the early identification of high-risk pregnancies and undertaking of the necessary measures to improve placentation [37]. Recent studies have demonstrated that algorithms combining maternal characteristics and biophysical and biochemical tests at 11-13 weeks could identify most pregnancies delivering preterm SGA neonates in the presence or absence of preeclampsia [34, 35]. Furthermore, evidence from metaanalyses of randomized studies utilizing the prophylactic use of low-dose aspirin in pregnancies at high risk of preeclampsia reported that such therapy initiated before 16 weeks' gestation can substantially reduce preeclampsia, fetal growth restriction and perinatal death [38, 39].

In $55 \%$ of our antepartum stillbirths, fetal death occurred at $\geq 32$ weeks' gestation, and in this group the birthweight was below the 10th percentile for GA in $38 \%$ of the cases. In this group, stillbirth could have been avoided by iatrogenic delivery, and failure to do so reflects the inadequacy of current antenatal care in the detection of severe fetal growth restriction. In the UK, ultrasound examination in the third trimester is not performed routinely, and the extent to which such a scan, as well as the timing and content of the scan, will identify and prevent stillbirths merits investigation.

\section{Acknowledgement}

This study was supported by a grant from the Fetal Medicine Foundation (Charity No. 1037116).

\section{References}

1 Gardosi J, Chang A, Kalyan B, Sahota D, Symonds EM: Customised antenatal growth charts. Lancet 1992;339:283-287.

2 Gardosi J, Mongelli M, Wilcox M, Chang A: An adjustable fetal weight standard. Ultrasound Obstet Gynecol 1995;6:168-174.

$>3$ Sahota DS, Kagan KO, Lau TK, Leung TY, Nicolaides KH: Customized birth weight: coefficients and validation of models in a UK population. Ultrasound Obstet Gynecol 2008;32:884-889.

$\checkmark 4$ Robinson HP, Fleming JE: A critical evaluation of sonar 'crown-rump length' measurements. BJOG 1975;82:702-710.

5 Nicolaides KH: Screening for fetal aneuploidies at 11 to 13 weeks. Prenat Diagn 2011;31: 7-15.
6 Brown MA, Lindheimer MD, de Swiet M, Van Assche A, Moutquin JM: The classification and diagnosis of the hypertensive disorders of pregnancy: statement from the International Society for the Study of Hypertension in Pregnancy (ISSHP). Hypertens Pregnancy 2001;20:IX-XIV.

7 World Health Organisation: Definition and diagnosis of diabetes mellitus and intermediate hyperglycaemia; report of a WHO/IDF consultation 2006;1-46; http://www.who. int/diabetes/publications/en, accessed Sep tember 2011.

$>8$ Poon LC, Karagiannis G, Staboulidou I, Shafiei A, Nicolaides KH: Reference range of birth weight with gestation and first-trimester prediction of small-for-gestation neonates. Prenat Diagn 2011;31:58-65.

$>9$ Altman DG: Construction of age-related reference centiles using absolute residuals. Stat Med 1993;12:917-924.
10 Zweig MH, Campbell G: Receiver-operating characteristic (ROC) plots: a fundamental evaluation tool in clinical medicine. Clin Chem 1993;39:561-577.

11 Gardosi J, Francis A: Customised weight centile calculator - GROW-Centile v.5.12/6.2 2009. Gestation Network, www.gestation. net (v. 5.12:individual; v 6.2:bulk centiles).

12 Gilbert WM, Young AL, Danielsen B: Pregnancy outcomes in women with chronic hypertension: a population-based study. J Reprod Med 2007;52:1046-1051.

13 Murphy HR, Steel SA, Roland JM, Morris D, Ball V, Campbell PJ, Temple RC, East Anglia Study Group for Improving Pregnancy Outcomes in Women with Diabetes (EASIPOD): Obstetric and perinatal outcomes in pregnancies complicated by Type 1 and Type 2 diabetes: influences of glycaemic control, obesity and social disadvantage. Diabet Med 2011;28:1060-1067. 
14 Yu CK, Khouri O, Onwudiwe N, Spiliopoulos Y, Nicolaides KH, Fetal Medicine Foundation Second-Trimester Screening Group: Prediction of pre-eclampsia by uterine artery Doppler imaging: relationship to gestational age at delivery and small-for-gestational age. Ultrasound Obstet Gynecol 2008; 31:310-313.

15 Catalano PM, McIntyre HD, Cruickshank JK, McCance DR, Dyer AR, Metzger BE, Lowe LP, Trimble ER, Coustan DR, Hadden DR, Persson B, Hod M, Oats JJ, the HAPO Study Cooperative Research Group: The Hyperglycemia and Adverse Pregnancy Outcome Study: associations of GDM and obesity with pregnancy outcomes. Diabetes Care 2012;35:780-786.

16 Centre for Maternal and Child Enquiries (CMACE). 2011. Perinatal Mortality 2009: United Kingdom. London, CMACE.

-17 Lawn JE, Blencowe H, Pattinson R, Cousens S, Kumar R, Ibiebele I, Gardosi J, Day LT, Stanton C, The Lancet's Stillbirths Series steering committee: Stillbirths: Where? When? Why? How to make the data count? Lancet 2011;377:1448-1463.

18 Willinger M, Ko CW, Reddy UM: Racial disparities in stillbirth risk across gestation in the United States. Am J Obstet Gynecol 2009; 201:469.e1-469.e8.

19 Sebire NJ, Jolly M, Harris JP, Wadsworth J, Joffe M, Beard RW, Regan L, Robinson S: Maternal obesity and pregnancy outcome: a study of 287,213 pregnancies in London. Int J Obes Relat Metab Disord 2001;25:11751182.

20 Stephansson O, Dickman PW, Johansson A, Cnattingius S: Maternal weight, pregnancy weight gain, and the risk of antepartum stillbirth. Am J Obstet Gynecol 2001;184:463469.

21 Syngelaki A, Bredaki FE, Vaikousi E, Maiz $\mathrm{N}$, Nicolaides KH: Body mass index at 11-13 weeks' gestation and pregnancy complications. Fetal Diagn Ther 2011;30:250-265.
22 Aliyu MH, Lynch O, Wilson RE, Alio AP, Kristensen S, Marty PJ, Whiteman VE, Salihu HM: Association between tobacco use in pregnancy and placenta-associated syndromes: a population-based study. Arch Gynecol Obstet 2011;283:729-734.

23 Chaveeva P, Carbone IF, Syngelaki A, Akolekar R, Nicolaides KH: Contribution of method of conception on pregnancy outcome after the 11-13 weeks scan. Fetal Diagn Ther 2011;30:9-22.

24 Fretts RC: Etiology and prevention of stillbirth. Am J Obstet Gynecol 2005;193:19231935.

25 Macintosh MC, Fleming KM, Bailey JA, Doyle P, Modder J, Acolet D, Golightly S, Miller A: Perinatal mortality and congenital anomalies in babies of women with type 1 or type 2 diabetes in England, Wales, and Northern Ireland: population based study. BMJ 2006;333:177.

26 Faiz AS, Demissie K, Rich DQ, Kruse L, Rhoads GG: Trends and risk factors of stillbirth in New Jersey 1997-2005. J Matern Fetal Neonatal Med 2012, Epub ahead of print.

27 Clausson B, Gardosi J, Francis A, Cnattingius $\mathrm{S}$ : Perinatal outcome in SGA births defined by customized versus populationbased birthweight standards. BJOG 2001; 108:830-834.

28 McCowan L, Harding JE, Stewart AW: Customized birthweight centiles predict SGA pregnancies with perinatal morbidity. BJOG 2005;112:1026-1033.

29 Odibo AO, Francis A, Cahill AG, Macones GA, Crane JP, Gardosi J: Association between pregnancy complications and smallfor-gestational-age birth weight defined by customized fetal growth standard versus a population-based standard. J Matern Fetal Neonatal Med 2011;24:411-417.

30 Ego A, Subtil D, Grange G, Thiebaugeorges $\mathrm{O}$, Senat MV, Vayssiere C, Zeitlin J: Customized versus population-based birth weight standards for identifying growth restricted infants: a French multicenter study. Am J Obstet Gynecol 2006;194:1042-1049.
1 Hutcheon JA, Zhang X, Platt RW, Cnattingius S, Kramer MS: The case against customized birthweight standards. Paediatr Perinat Epidemiol 2011;25:11-16.

- 32 Akolekar R, Bower S, Flack N, Bilardo CM, Nicolaides KH: Prediction of miscarriage and stillbirth at 11-13 weeks and the contribution of chorionic villus sampling. Prenat Diagn 2011;31:38-45.

- 33 Akolekar R, Syngelaki A, Sarquis R, Zvanca $\mathrm{M}$, Nicolaides KH: Prediction of early, intermediate and late pre-eclampsia from maternal factors, biophysical and biochemical markers at 11-13 weeks. Prenat Diagn 2011; 31:66-74.

34 Poon LC, Karagiannis G, Staboulidou I, Shafiei A, Nicolaides KH: Reference range of birth weight with gestation and first-trimester prediction of small-for-gestation neonates. Prenat Diagn 2011;31:58-65.

- 35 Karagiannis G, Akolekar R, Sarquis R, Wright D, Nicolaides KH: Prediction of small-for-gestation neonates from biophysical and biochemical markers at 11-13 weeks. Fetal Diagn Ther 2011;29:148-154.

36 Greco E, Gupta R, Syngelaki A, Poon LCY, Nicolaides KH: First trimester screening for spontaneous preterm delivery with maternal characteristics and cervical length. Fetal Diagn Ther 2012;31:154-161.

37 Nicolaides KH: Turning the pyramid of prenatal care. Fetal Diagn Ther 2011;29:183196.

38 Bujold E, Roberge S, Lacasse Y, Bureau M, Audibert F, Marcoux S, Forest JC, Giguère Y: Prevention of preeclampsia and intrauterine growth restriction with aspirin started in early pregnancy: a meta-analysis. Obstet Gynecol 2010;116:402-414.

39 Roberge S, Villa P, Nicolaides K, Giguère Y, Vainio M, Bakthi A, Ebrashy A, Bujold E: Early administration of low dose aspirin for the prevention of preterm and term pre-eclampsia: a systematic review and meta-analysis. Fetal Diagn Ther 2012;31:141-146. 